\title{
Healthy Living: High Blood Pressure ${ }^{1}$
}

\author{
Linda B. Bobroff and Leigh Ann Martin²
}

\section{What Is High Blood Pressure?}

High blood pressure is increased pressure of blood inside the blood vessels. Too much pressure causes more work for the heart. Another name for high blood pressure is hypertension. About one in three American adults has hypertension and about half of them do not know they have this health problem.

Hypertension can cause the following:

- Atherosclerosis (narrowing and hardening of blood vessels)

- Heart attack

- Stroke

- Kidney failure

- Damage to the eyes

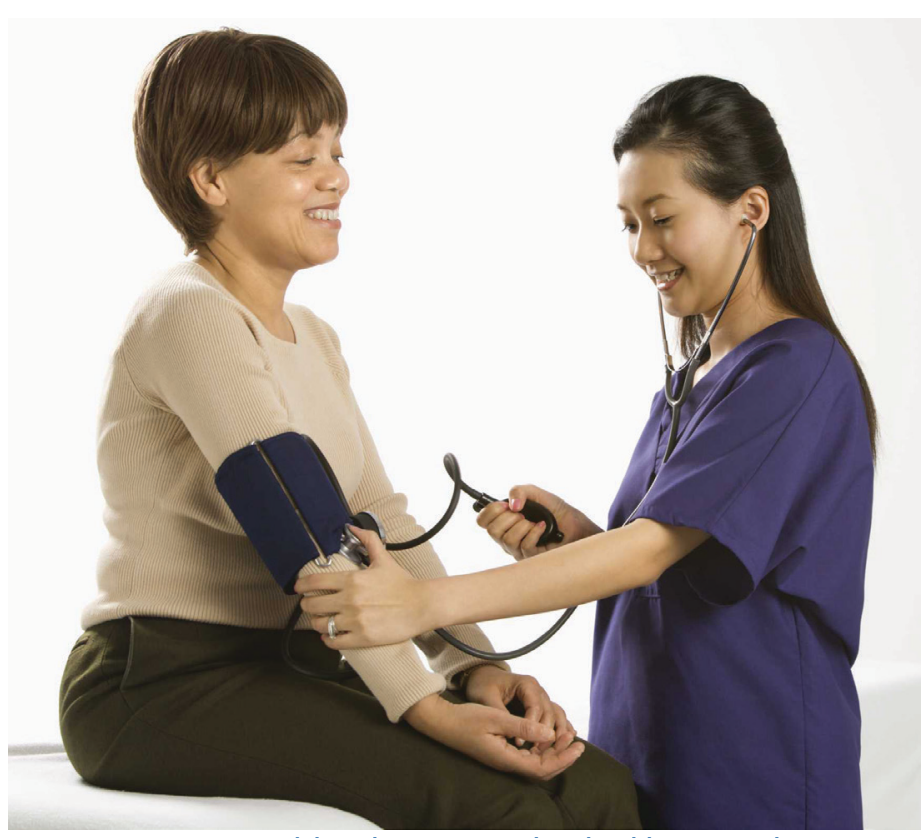

Flgure 1. Have your blood pressure checked by your doctor or other health care provider at least once a year. Credits: Ron Chapple Studios

\section{Am I at Risk?}

You are at higher risk of developing hypertension if you:

- are African-American

- are a man

1. La versión en español de este documento es Vida Saludable: Presión sanguínea (FCS8599-Span). This document is FCS8599, one of a series of the Department of Family, Youth and Community Sciences, UF/IFAS Extension. Original publication date: March 2004. Latest revision: September 2013. Please visit the EDIS website at http://edis.ifas.ufl.edu.

2. Linda B. Bobroff, PhD, RD, LD/N, professor, and Leigh Ann Martin, former ENAFS coordinator, Department of Family, Youth and Community Sciences; UF/IFAS Extension, Gainesville, FL 32611. 
- are 45 years of age or older

- eat a high-sodium diet

- are overweight

- had a parent with hypertension

- drink large amounts of alcohol

- are not physically active

\section{What Is Normal Blood Pressure?}

Blood pressure is measured as two numbers-the systolic (sis-TOL-ik) and diastolic (di-ah-STOL-ik) pressures. Blood pressure is measured as millimeters of mercury or $\mathrm{mmHg}$. The two numbers are written as systolic "over" diastolic, such as 120/80 mmHg. Most people should aim for a blood pressure less than $120 / 80 \mathrm{mmHg}$. This means systolic pressure should be less than $120 \mathrm{mmHg}$ and diastolic pressure should be less than $80 \mathrm{mmHg}$.

\section{Check Your Blood Pressure}

Often there are no symptoms of high blood pressure. Checking your blood pressure is the only way to know if your blood pressure is high. Have your blood pressure checked by a doctor or other health professional at least once a year. The Elder Nutrition and Food Safety (ENAFS) program's Keep Track of Your Blood Pressure log (http://edis.ifas.ufl.edu/ fy662) can help you monitor your blood pressure between doctor visits.

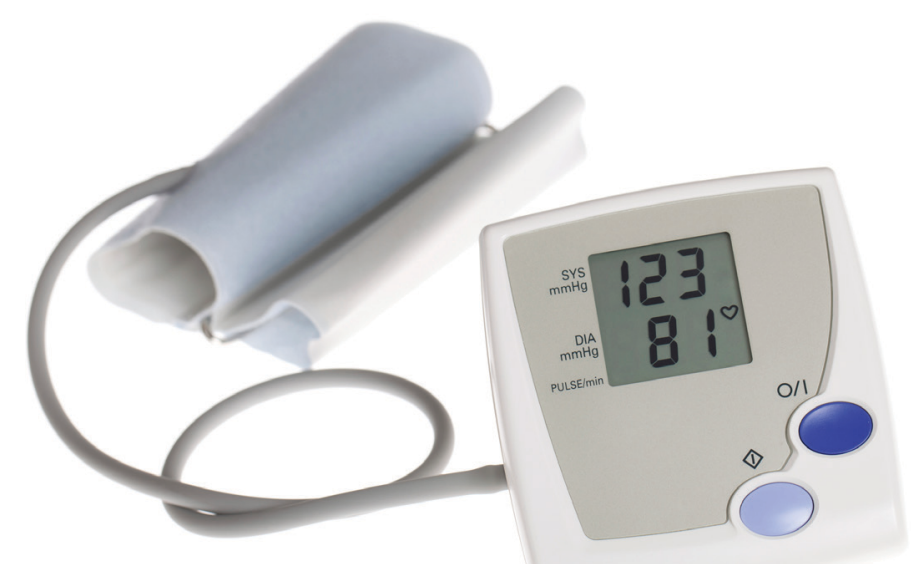

Figure 2. It is possible to keep track of your blood pressure at home. You can then share the numbers with your doctor at your regular checkups.

Credits: iStockphoto 